\title{
NEUROSTEROIDS: \\ THELONG JOURNEY TO CLINICAL USE
}

\author{
V. Patchev \\ ExSciMed Consulting, Germany, 82223, Eichenau
}

DOI: 10.19163/MedChemRussia2021-2021-81

E-mail:mail@exscimed.com

Sedative and anesthetic properties of ring-A-modified steroids have been documented and used since more than 40 years. Interest in brain-derived neuroactive steroids experienced a major boost by the discovery of their action as allosteric modulators of the GABAA receptor. In the past convincing evidence has accumulated for the involvement of neurosteroids in the regulation of the response to stress, and various prospects of their therapeutic use in neurological and psychiatric conditions were explored. However, the expectations of broad clinical use remain vague, due to the multifarious neurochemical interactions of neurosteroids, as well as to the paucity of proprietary compounds which warrant IP protection and commercial exploitability. 